\title{
Role of oral inositol supplementation in women with polycystic ovarian syndrome
}

\author{
Najma Malik*, Navneet Dubey \\ Department of Obstetrics and Gynecology, BRD Medical College Gorakhpur, Uttar Pradesh, India
}

Received: 11 September 2021

Revised: 24 October 2021

Accepted: 25 October 2021

*Correspondence:

Dr. Najma Malik,

E-mail: najmamalik80@gmail.com

Copyright: $\odot$ the author(s), publisher and licensee Medip Academy. This is an open-access article distributed under the terms of the Creative Commons Attribution Non-Commercial License, which permits unrestricted non-commercial use, distribution, and reproduction in any medium, provided the original work is properly cited.

\begin{abstract}
Background: PCOS is one of the most common endocrine disorder in women of reproductive age, it affects about 5$10 \%$ of women of reproductive age. It is characterized by chronic anovulation, hyperandrogenism, and insulin resistance. $30-40 \%$ of PCOS women have impaired glucose tolerance.

Methods: This was prospective observational study carried out on 100 patients of PCOS visiting outpatient Department of Obstetrics and Gynecology, BRD Medical College, Gorakhpur from $1^{\text {st }}$ July 2018 to $30^{\text {th }}$ June 2019. Patients were diagnosed as PCOS on basis of Rotterdam criteria. In these 100 patients, oral inositol $2 \mathrm{gm}$ twice daily was given for 3 months to 6 months depending upon the response of the patient and patients were examined every 4 week for menstrual regularity, acne improvement, hirsutism, spontaneous ovulation and pregnancy.

Results: With inositol supplementation, menstrual abnormality corrected in $80 \%$ cases, $45 \%$ cases having acne improved. Ovulation occurred in $75.5 \%$ cases and $66.6 \%$ cases conceived with inositol supplementation.

Conclusions: Insulin resistance is the basic pathophysiology for PCOS hence inositol supplementation is supposed to be very good medicine for management of PCOS to improve insulin sensitivity. Inositol leads to improvement in regularity of menstrual cycle, insulin resistance, hyperandrogenic features like hirsutism, acne, restores ovulation and improves oocyte quality.
\end{abstract}

Keywords: Inositol, Insulin resistance, Myoinositol, PCOS

\section{INTRODUCTION}

PCOS is one of the most common endocrine disorder in women of reproductive age, it affects about $5-10 \%$ of women of reproductive age who suffer from obesity, hyperandrogenism, ovarian dysfunction and menstrual irregularities.

Both aetiology and diagnosis of the syndrome is controversial. According to Rotterdam criteria developed in 2003, PCOS is diagnosed when there is presence of two of the following three conditions- 1) oligomenorrhea and/or anovulation, 2) clinical and/or biochemical signs of hyperandrogenism that may be associated with hirsutism, 3) polycystic ovaries on ultrasonography. ${ }^{1}$
Although not included as criteria, insulin resistance and hyperinsulinemia are important etiologic factors associated with typical clinical signs and hormonal disorders of PCOS. Insulin resistance along with hyperinsulinemia affects $40-50 \%$ of PCOS patients both lean and obese. ${ }^{2}$

The exact cause of insulin resistance observed in PCOS women is unknown, although a post receptor defect that could affect glucose transport has been proposed. ${ }^{3-4}$ Further studies have suggested that impairment in the insulin pathway could be due to a defect in the inositolphosphoglycans (IPGs) second messanger. ${ }^{5-6}$ In PCOS women a defect in tissue availability or altered metabolism of inositol or IPGs mediators may contribute 
to insulin resistance. ${ }^{7}$ Hyperinsulinemia could induce an excess of androgen production in PCOS women through two different ways: first one is direct stimulation of ovaries to produce androgens and the other one is the reduction of sex hormone binding globulin (SHBG) serum level. ${ }^{8}$ Isoforms of inositol belongs to the vitamin $\mathrm{B}$ complex. Epimerization of the six hydroxyl group of inositol leads to formation of 9 stereo isomers including myoinositol (MI) and D-chiroinositol. D-chiroinositol (DCI) is involved in insulin mediated androgen synthesis, whereas MI mediate glucose uptake and follicular stimulating hormone (FSH) signalling. Reduced intraovarian myoinositol adversely affect glucose uptake and metabolism of both oocyte and follicular cells. Since oocyte are characterized by high glucose consumption, this would compromise oocyte quality. MI and DCI are intracellularly incorporated in to inositolphosphoglycan (IPGs) which are second messengers of insulin and some actions of insulin are mediated by these IPGs mediators. Epimerase conversion of MI to DCI is under insulin control. The excess insulin enhanced action of the epimerase in the ovary, resulting in excessive conversion of MI to DCI which results in increased DCI and reduced MI in ovary, leading to lack of second messenger. A ratio of 40:1 (MI:DCI) is thought to be physiological for most tissues. $^{9}$

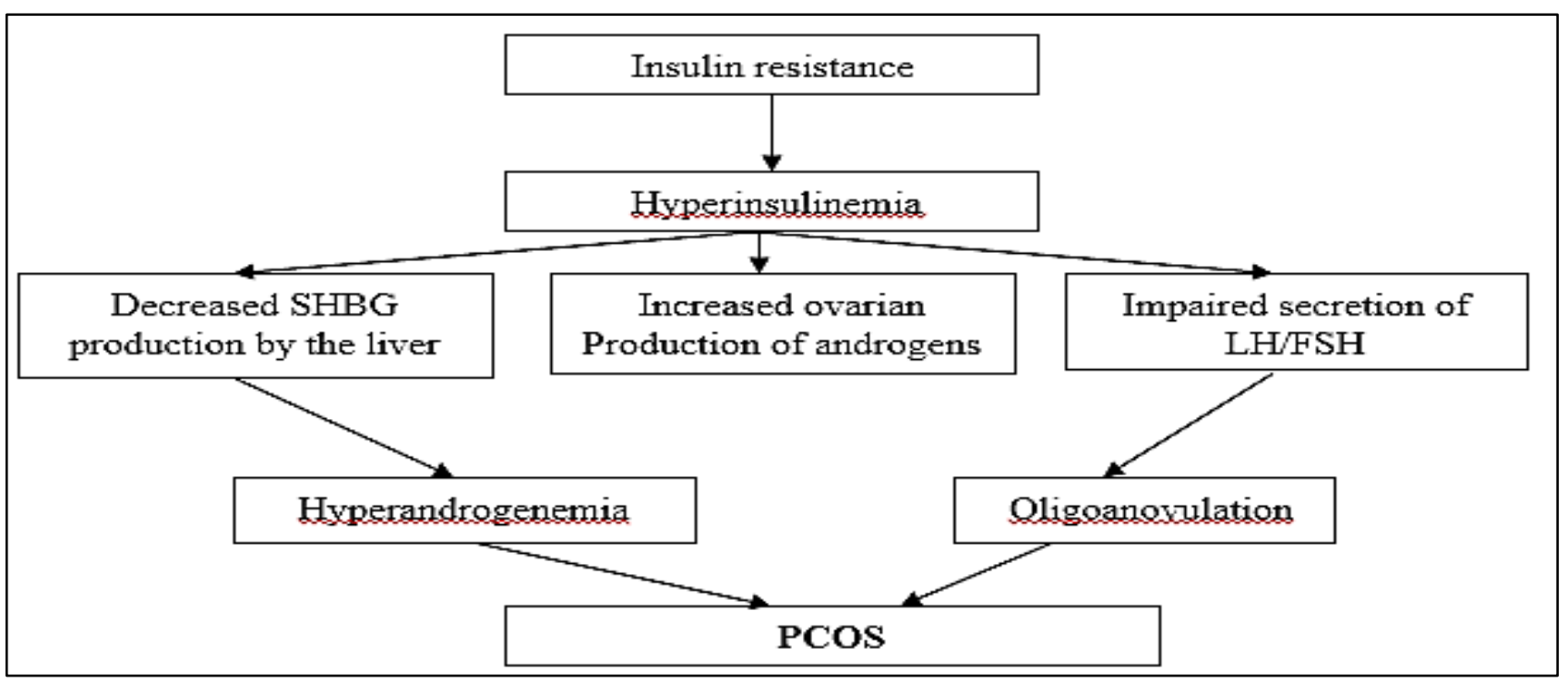

Figure 1: Insulin resistance and development of PCOS.

Due to association between PCOS and insulin resistance, insulin sensitizers have been used in the therapy of PCOS. Previous studies have shown the use of metformin, troglitazone or myoinositol reduces serum androgens and improves ovulation in women with PCOS. Several clinical studies have highlighted the usefulness of inositol supplementation in PCOS. Also it has been proven to be safe even after high dose consumption. ${ }^{10}$

The aim of this study was to observe the effectiveness of oral myoinositol supplementation in PCOS women for menstrual irregularities, cutaneous hyperandrogenic resolution and for the effectiveness on ovulation and pregnancy rate.

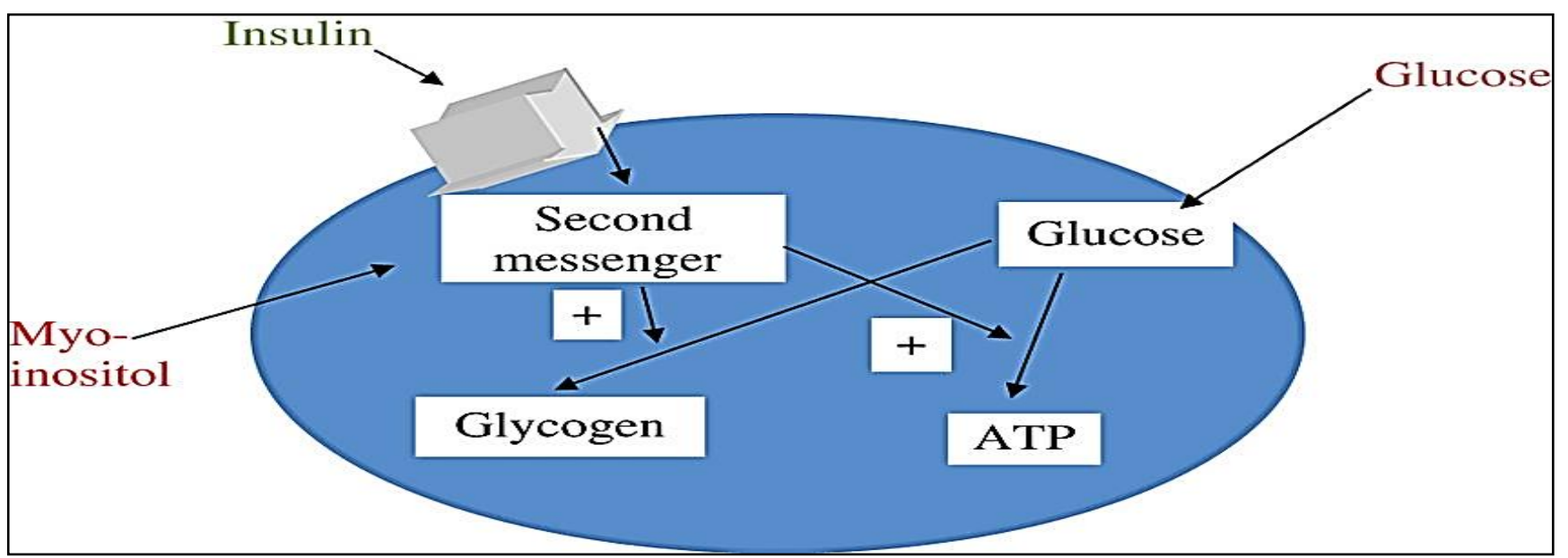

Figure 2: Mechanism of action of myoinositol in the cell. 


\section{METHODS}

This study was prospective observational study carried out on 100 patients of PCOS visiting outpatient Department of Obstetrics and gynaecology, BRD Medical College, Gorakhpur from $1^{\text {st }}$ July 2018 to $30^{\text {th }}$ June 2019.

Detailed history of all patients taken and physical examination done after taking informed consent. Patients were diagnosed as PCOS if two out of the three following features were present (Rotterdam's criteria 2003)- 1) oligomenorrhea and/or anovulation, 2) polycystic ovaries on ultrasonography, 3) clinical and/or biochemical sign of hyperandrogenism that may be associated with hirsutism.

All routine investigations including $75 \mathrm{gm}$ oral glucose tolerance test (GTT), Hba1c and lipid profile done. Along with this hormonal profile like serum levels of follicle stimulating hormone (FSH), luteinizing hormone (LH), prolactin (PRL), testosterone (total and free), thyroid stimulating hormone (TSH) done. Ultrasonography (transabdominal/transvaginal) was done to see polycystic ovarian morphology.

\section{Inclusion criteria}

Patients of PCOS in the reproductive age group (15-49) visiting to Obstetrics and Gynecology outpatient department, BRD Medical College, Gorakhpur.

\section{Exclusion criteria}

Patients having menstrual irregularities, hyperandrogenic features, ovulatory dysfunctions and infertility due to other pathologies apart from PCOS were not included in this study.

After confirmation of diagnosis and taking consent from these patients, they were advised oral myoinositol $2 \mathrm{gm}$ twice daily for 3 months to 6 months depending upon the response of the treatment. Patients were examined every 4 week for menstrual regularity, acne improvement, hirsutism, spontaneous ovulation and pregnancy.

\section{Data analysis}

Data analysis was done using statistical package for the social statistics (SPSS) 16 software. Data was summarized in tables. Results are presented in percentage. No statistical test was applied.

\section{RESULTS}

Socio-demographic profile of PCOS patients shows maximum no. of cases (37\%) belonged to 21-25 years of age followed by $15-20$ years of age $(33 \%)$. Unmarried women/girls having PCOS were $55 \% .60 \%$ cases belonged to upper class and from urban area. Only $40 \%$ women were having normal weight rest $60 \%$ were of higher weight (Table 1).

Table 1: Distribution of cases on basis of demographic characteristics.

\begin{tabular}{|lll|}
\hline Variables & No. of cases & Percentage \\
\hline Age group (years) & & \\
\hline $15-20$ & 33 & 33 \\
\hline $21-25$ & 37 & 37 \\
\hline $26-30$ & 25 & 25 \\
\hline $31-35$ & 05 & 05 \\
\hline Socioeconomic status & & \\
\hline Lower & 10 & 10 \\
\hline Middle & 30 & 30 \\
\hline Upper & 60 & 60 \\
\hline Education & & \\
\hline Illiterate & 10 & 10 \\
\hline Literate & 90 & 90 \\
\hline Residence & & \\
\hline Urban & 60 & 60 \\
\hline Rural & 40 & 40 \\
\hline Marital status & & \\
\hline Married & 45 & 45 \\
\hline Unmarried & 55 & 55 \\
\hline BMI (kg/m ${ }^{2}$ ) & & 50 \\
\hline Normal (<24.9) & 40 & 55 \\
\hline Overweight (25.0-29.9) & 55 & 5 \\
\hline Obese (30 or more) & 5 & \\
\hline
\end{tabular}

Most common symptom was menstrual abnormality found in $100(100 \%)$ cases followed by infertility $45(45 \%)$ cases and hyperandrogenic feature like acne and hirsutism were present in 35 (35\%) cases (Table 2).

Oligomenorrhoea was most common menstrual irregularity found in $70 \%$ of women. $10 \%$ women having combination of oligomenorrhoea and hypomenorrhea, rest $20 \%$ come with history of irregular menstrual cycles (Table 3).

Table 2: Distribution of cases according to symptoms.

\begin{tabular}{|lll|}
\hline Symptoms & No. of cases & Percentage \\
\hline Menstrual abnormality & 20 & 20 \\
\hline $\begin{array}{l}\text { Menstrual abnormality + } \\
\text { acne }\end{array}$ & 08 & 08 \\
\hline $\begin{array}{l}\text { Menstrual abnormality + } \\
\text { hirsutism }\end{array}$ & 15 & 15 \\
\hline $\begin{array}{l}\text { Menstrual abnormality + } \\
\text { hyperandrogenic features } \\
\text { (acne + hirsutism) }\end{array}$ & 12 & 12 \\
\hline $\begin{array}{l}\text { Menstrual abnormality + } \\
\text { infertility }\end{array}$ & 45 & 45 \\
\hline Total & 100 & 100 \\
\hline
\end{tabular}


Table 3: Distribution of cases according to type of menstrual abnormality.

\begin{tabular}{|lll|}
\hline Menstrual abnormality & No. of cases & Percentage \\
\hline Oligomenorrhoea & 70 & 70 \\
\hline $\begin{array}{l}\text { Oligomenorrhoea }+ \\
\text { hypomenorrhea }\end{array}$ & 10 & 10 \\
\hline Irregular menstruation & 20 & 20 \\
\hline Total & 100 & 100 \\
\hline
\end{tabular}

Table 4: Average weight loss in patient after taking inositol.

\begin{tabular}{|lll|}
\hline BMI $\left(\mathrm{kg} / \mathrm{m}^{2}\right)$ & \multicolumn{2}{l|}{ Weight loss $(\mathrm{kg}) / \mathrm{month}$} \\
\hline In over weight $(\mathbf{2 5 . 0 - 2 9 . 9 )}$ & 0.25 & 0.5 \\
\hline In obese (30 or more) & 0.5 & 0.75 \\
\hline
\end{tabular}

In our study average weight loss after taking inositol in overweight patients was $0.25-0.5 \mathrm{~kg} / \mathrm{month}$ while in obese patients it was $0.5-0.75 \mathrm{~kg} / \mathrm{month}$ (Table 4 ).

Table 5: Results after myoinositol treatment.

\begin{tabular}{|l|l|l|}
\hline & $\begin{array}{l}\text { No. of } \\
\text { cases/total } \\
\text { no. of cases }\end{array}$ & Percentage \\
\hline $\begin{array}{l}\text { Menstrual } \\
\text { abnormality corrected } \\
\text { with inositol }\end{array}$ & $80 / 100$ & 80 \\
supplementation & $9 / 20$ & 45 \\
\hline $\begin{array}{l}\text { Acne improved with } \\
\text { inositol } \\
\text { supplementation }\end{array}$ & $34 / 45$ & 75.5 \\
\hline $\begin{array}{l}\text { Ovulation occurred } \\
\text { with inositol } \\
\text { supplementation }\end{array}$ & & \\
\hline $\begin{array}{l}\text { Infertile cases } \\
\text { conceived with inositol } \\
\text { supplementation }\end{array}$ & $30 / 45$ & 66.6 \\
\hline
\end{tabular}

Table 5 shows results after 3-6 months therapy with myoinositol. Menstrual abnormality corrected in $80 \%$ cases, $45 \%$ cases having acne improved. Ovulation occurred in $75.5 \%$ cases and $66.6 \%$ cases conceived with inositol supplementation.

\section{DISCUSSION}

PCOS is a common endocrine disorder affecting women of reproductive age group. In our study we found $95 \%$ of cases were below age 30 years and only $5 \%$ above 30 years (mean age was $22.98 \pm 4.43$ years). Mean age among PCOS patients was $27 \pm 7.7$ in study done by Murlidhara et al in KMC Manglore. Monika et al and Spandana et al also observed PCOS is more common in this age group. ${ }^{11-13}$

Insulin resistance is a key factor in the pathogenesis of anovulation and hyperandrogenism in PCOS patients and insulin resistance is significantly exacerbated by obesity.

We observed that $55 \%$ patients were overweight, 5\% obese and rest $40 \%$ were of normal weight in our study. After giving myoinositol the average weight loss in overweight patients was $0.25-0.5 \mathrm{~kg} / \mathrm{month}$. Rim et al compared the effect of inositol (ovacure) alone to inositol and metformin (ovacure+metformin). They found $2.7 \mathrm{~kg}$ weight loss in inositol group compared to $4.64 \mathrm{~kg}$ in inositol+metformin group after 6 month of treatment. Reduction in weight was more in group using combined myoinositol and metformin. ${ }^{14}$

Our study showed 100 (100\%) of PCOS patients suffering from various kind of menstrual irregularities along with other features of PCOS. Menstrual regularity was achieved in $80(80 \%)$ cases within 3 to 6 month of inositol supplementation who were having oligomenorrhoea \pm hypomenorrhea. In study done by Genazzani et al, all patients under myoinositol $2 \mathrm{gm}$ with folic acid $200 \mu \mathrm{g}$ administration reported menstrual cycles during 12 week treatment. ${ }^{15}$ Similarly Venturella et al and Le Donne et al had shown significant improvement in menstrual abnormality in their studies. ${ }^{16,17}$

Being a insulin sensitizer myoinositol improves insulin sensitivity thereby reduces androgen levels.

So its use benefits in cutaneous disorder of hyperandrogenism (acne, hirsutism). Out of 20 women having acne, $9(45 \%)$ cases improved with inositol supplementation. In study of Monika el al. 2017 only $33.3 \%(5 / 15)$ had improvement in acne. ${ }^{12}$ In studies of Minozzi et al and Zacche et al they found significant reduction in problem of hirsutism. ${ }^{18,19}$

Ovulatory dysfunction is very common in PCOD women Raffone et al compared the effects of metformin and myoinositol on PCOS patients, total 120 patients were recruited, 60 patients were treated with metformin and 60 patients were treated with myoinositol. Among the patients treated with myoinositol spontaneous ovulation restored in $65 \%$ patients which is higher than metformin $(50 \%) .{ }^{20}$

Pedro-Antonio et al observed after 2-3 month of inositol supplementation among 3602 patients with PCOS $70 \%$ of women restored ovulation. ${ }^{21}$ These results were similar to our study, ovulation occurred in $75.5 \%$ cases within 3-6 months of inositol supplementation.

Many studies demonstrated myoinositol improves the pregnancy rate in PCOS women suffering from infertility. It might be due to decreasing insulin resistance leads to improved oocyte quality and development of mature oocytes. This effect of MI can be supported by our own study data as out of 45 infertile women, $30(66.67 \%)$ women conceived within 3-6 months of MI supplementation. In study of Raffone et al, it could be shown that the number of pregnancies was clearly higher in the myoinositol group than in the metformin group of 
patients. ${ }^{20}$ While in study of Papaleo et al and Riju Angik et al the conception rate was $40 \%$ and $36.84 \% .^{22,23}$

Limitations of the study are though the sample size and study duration was small, further research with larger samples and longer study periods is required to support the role of myoinositol treatment for PCOS. HOMA-IR (homeostatic model assessment for insulin resistance) not used to test insulin resistance due to unavailability of this test at our institution. Ferriman-Gallawey (FG) score not used to quantify hirsutism because most of unmarried patients did not gave consent. We assess hirsutism only on exposed areas like face and arms.

\section{CONCLUSION}

Insulin resistance is the basic pathophysiology for PCOS, hence inositol supplementation is supposed to be a very good medicine for management of PCOS to improve insulin sensitivity. Myoinositol lead to improvement in regularity of menstrual cycle, insulin resistance, hyperandrogenic features like hirsutism, acne, polycystic ovarian morphology, hormonal parameter and reproductive axis (restores ovulation and improves oocyte quality). MI is a safe and simple treatment that is able to restore spontaneous fertility in most PCOS patients with infertility. Most of infertile women on inositol do not require ovulation induction drug. Along with diet control and exercise (obese PCOS), myoinositol must be used as a first line drug for treatment of various complaints in PCOS patients.

\section{ACKNOWLEDGMENTS}

Authors would like to thank all study participants for their cooperation and providing the necessary information.

Funding: No funding sources

Conflict of interest: None declared

Ethical approval: The study was approved by the Institutional Ethics Committee

\section{REFERENCES}

1. The Rotterdam ESHRE/ASRM Sponsored PCOS Consensus Workshop Group. Revised 2003 consensus on diagnostic criteria and long-term health risks related to polycystic ovary syndrome (PCOS). Hum Reprod. 2004;19(1):41-7.

2. Ciampelli M, Fulghesu AM, Cucinelli F, Pavone V, Ronsisvalle E, Guido M, et al. Impact of insulin and body mass index on metabolic and endocrine variables in polycystic ovary syndrome. Metabolism. 1999;48(2):167-72.

3. Baillargeon JP, Nestler JE. Commentry: polycystic ovary syndrome; a syndrome of ovarian hypersensitivity to insulin? J Clin Endocrinol Metab. 2006;91:22-4.
4. Dunaif A. Insulin resistance and the polycystic ovary syndrome: mechanism and implications for pathogenesis. Endocr Rev. 1997;18.

5. Kennington AS, Hill CR, Craig J, Bogardusc, Raz I, Ortyer HK, et al. Low urinary chiro-inositol excretion in non-insulin dependent diabetes mellitus. $\mathrm{N}$ Engl $\mathbf{J}$ Med. 1990;323;373-8.

6. Asplin I, Galasko G, Larner J. Chiro-inositol deficiency and insulin deficiency .a comparison of the chiro-inositol and the myo-inositol containing insulin mediators isolated from urine, hemodialysate, and muscles of control and type II diabetes subjects. Proc Nat Acad Sci USA. 1993;90:5924-8.

7. Baillargeon JP, Diamanti-Kandarakis E, Ostlund RE, Apridonidze T, Iuorno MJ, Nestler JE. Altered Dchiro-inositol urinary clearance in women with polycystic ovary syndrome. Diabetes Care. 2006;29(2):300-5.

8. Croze MI, Soulage CO. Practical role and therapeutic interest of myoinositol in metabolic diseases. Biochimie, 2013;95(10):1811-27.

9. Bizzarri M, Carlomagno G. Inositol: history of an effective therapy for polycystic ovary syndrome. Eur Rev Med Pharmacol Sci. 2014;18:1896-903.

10. Carlomagno G, Unfer V. Inositol safety: clinical evidences. Eur Rev Med Pharmacol Sci. 2011;15(8):931-6.

11. Murlidhara KD, Adhikari PM, Murlidhara DV. Overweight/obesity and metabolic syndrome in women with polycystic ovary syndrome. Indian $\mathbf{J}$ Basic Applied Med Res. 2015;4(3):227-36.

12. Ranwa M, Nagaria T, Jaiswal, Arya A. Study of effect of myoinositol on menstrual irregularities and skin problems in polycystic ovarian syndrome cases. Int $\mathbf{J}$ Reprod Contracept Obstet Gynecol 12017;6(6):23107.

13. Spandana JC. A study on the clinical, biochemical and hormonal profile of polycystic ovary syndrome patients attending tertiary care hospital. Int J Reprod Contraception, Obstet Gynecol. 2017;6(5):1987.

14. Hanna R, Wehbe T, Abou Jaoude E. Metabolic effects of D-chiro-inositol and myo-inositol in polycystic ovary syndrome. Int $\mathbf{J}$ Clin Endocrinol Metab. 2017;3(1):029-33.

15. Genazzani F, Jassoni VN. Myoinositol administration positively affects hyperinsulinemia and hormonal parameters in overweight patients with polycystic ovary syndrome. Gynecol Endocrinol. 2008:24;13944.

16. Venturella R, Mocciaro R, De Trana E, D'Alessandro P, Morelli M, Zullo F. Assessment of the modification of the clinical, endocrinal and metabolical profile of patients with PCOS syndrome treated with myoinositol. Minerva Ginecol. 2012;64(3):239-43.

17. Le Donne M, Alibrandi A, Giarrusso R, Lo Monaco, Muraca U. Diet, metformin and inositol in overweight and obese women with polycystic ovary syndrome: effects on body composition. Minerva Ginecol. 2012;64(1):23-9. 
18. Minozzi M, Costantino D, Guaraldi C, Unfer V. The effect of a combination therapy with myoinositol and a combined oral contraceptive pill versus a combined oral contraceptive pill alone on metabolic, endocrine and clinical parameters in PCOS. Gynecol Endocrinol. 2011;27(11):920-4.

19. Zacche MM, Caputo L, Fillipis S, Zacche G, Dindelli M, Ferrari A. Efficacy of myoinositol in the treatment of cutaneous disorders in young women with polycystic ovary syndrome. Gynecol Endocrinol. 2009;25:508-13.

20. Raffone E, Rizzo P, Benedetto V. Insulin sensitiser agents alone and in co-treatment with r-FSH for ovulation induction in PCOS women. Gynecol Endocrinol. 2010;26(4):275-80.

21. Regidor PA, Schindler AE. Myoinositol as a safe and alternative approach in the treatment of infertile PCOS women: a German observational study. Int J Endocrinol. 2016;2016.
22. Papaleo E, Unfer V, Baillargeon JP, De Santis L, Fusi $\mathrm{F}$, Brigante $\mathrm{C}$, et al. Myo-inositol in patients with polycystic ovary syndrome: a novel method for ovulation induction. Gynecol Endocrinol. 2007;23(12):700-3.

23. Angik R, Jajoo SS, Hariharan C, Chimote A. A comparative study of metabolic and hormonal effects of myoinositol versus metformin in women with polycystic ovary syndrome: a randomised controlled trial. Int $\mathbf{J}$ Reprod Contracept Obstet Gynecol. 2015;4(1):189-95.

Cite this article as: Malik N, Dubey N. Role of oral inositol supplementation in women with polycystic ovarian syndrome. Int J Reprod Contracept Obstet Gynecol 2021;10:4493-8. 